\title{
La pasión por Dios vivida en la com-pasión por las víctimas Esencia de la vida religiosa
}

\author{
Martha Zechmeister, C.J., \\ Centro de Reflexión Teológica
}

\section{Punto de partida. La situación actual de la vida religiosa}

Una sobria mirada a nuestro mundo nos enseña que la vida religiosa en Europa $^{1}$ está gravemente enferma, si no moribunda. En un proceso acelerado está desapareciendo de la percepción pública y adentrándose en la invisibilidad. Si las estadísticas tienen razón, dentro de poco llegaremos a ser una nota marginal en el paisaje europeo. Quienes ayer fueron constructores de los fundamentos de la cultura europea se convierten hoy en recuerdo histórico, y se difuminan en la insignificancia. Además, muchas veces parece que hemos perdido nuestra "mística", término que usamos, por el momento, en el sentido popular latinoamericano. "Mística" es nuestra inspiración, el sentir de una dinámica que nos sustenta y empuja, que nos atrae y nos hace vibrar con satisfacción y gozo, como individuos y como comunidad.

"La vuelta a los fundadores, a la fuente del propio carisma" fue el lema del Vaticano II para la vida religiosa. Y muchas congregaciones hemos vivido este proceso de renovación al volver a nuestro carisma de origen de forma intensa y sincera. Pero la crisis es tan radical y general que no basta con volver a los fundadores de las diversas congregaciones. Toda la vida religiosa está afectada por la crisis, y por ello tenemos que volver, de verdad, a los comienzos, a

1. Este artículo es el texto revisado de una conferencia en la 40. ${ }^{\text {a }}$ Semana nacional para institutos de vida consagrada, 26-30 de abril de 2011, en Madrid, bajo el título "Yo no hago nada por mí mismo", o la mística de la misión. Por esta razón, en este texto se encuentran alusiones a la situación de la vida religiosa en Europa. El título actual lo debo a la formulación de Johann Baptist Metz "La pasión por Dios como compasión, como mística política de la compassio", en Memoria passionis. Una evocación provocadora en una sociedad pluralista, Santander, 2007, p. 165. 
la fuente madre 2 . Para reencontrar nuestra "mística" necesitamos volver al principio de toda vida religiosa y de todo cristianismo. Este principio es Jesús, y tal como nos enseñó Karl Rahner, "principio" es más que un comienzo temporal. "Principio es lo que contiene el "todo en germen", el origen que configura todo lo que se va a desarrollar desde esta simiente ${ }^{3}$.

\section{La vuelta a los orígenes}

Si no nos engañamos, la vuelta al origen nos ofrece una primera sorpresa: en los inicios del movimiento de Jesús no hay ninguna "vida religiosa", ciertamente no en el sentido técnico de la palabra, una comunidad de hombres o mujeres célibes. Jesús no fue monje, tampoco sus discípulos. Desde su origen, el cristianismo no ha sido una religión monacal, como lo es, por ejemplo, el budismo. El origen, el corazón del budismo, es la sangha, la comunidad de los monjes. En el cristianismo, por el contrario, pasaron siglos, siglos canónicamente decisivos, para la configuración de la identidad cristiana, hasta que aparecieron los primeros anacoretas con los cuales comienzan las tradiciones que, más tarde, se llamarán órdenes o vida religiosa.

Además, la ambigüedad de los orígenes del monacato cristiano es obvia. No se puede negar en ellos la influencia gnóstica que entrañaba el peligro de desfigurar el Evangelio de manera profunda y sutil. En la "fuga mundi" de los "padres del desierto" se deja notar un dualismo que rechaza y menosprecia no solamente la "realidad externa", histórica y política, sino que también afecta al cuerpo humano, pues con frecuencia está transida de una obsesión notablemente enfermiza por reprimir la sexualidad. En estos orígenes del monacato nos encontramos con ideales de ascesis, santidad y perfección que tienen poco o nada que ver con el camino de Jesús. Todo ello ha dejado huellas profundas y deshumanizantes en el cristianismo en general y en la vida religiosa en particular.

Sin embargo, también es verdad que la masiva "fuga mundi" de los anacoretas, esos personajes raros y extravagantes del siglo IV, tiene otros rasgos que no provienen de la gnosis ni del neoplatonismo. Es la enérgica protesta en contra de una Iglesia imperial y en contra de su matrimonio con el poder: en aquel momento histórico la Iglesia dejaba de ser una minoría perseguida y se encontraba en un acelerado proceso de adaptación y asimilación a la cultura dominante. Eso no significaba solo su necesaria acomodación a nuevos tiempos,

2. Esta y otras ideas inspiradoras las debo al excelente estudio de José M. Castillo El futuro de la vida religiosa. De los orígenes a la crisis actual, Trotta, Madrid, 2003, pp. 25 y ss.

3. 'Por 'principio' no ha de entenderse aquí simplemente un primer período de un tiempo más amplio, sino que el término ha de entenderse en el sentido de árjé, como principium que contiene el 'todo en germen'..." (K. Rahner, "Historia de la teología”, en Sacramentum Mundi, VI, Herder, Barcelona, 1976, p. 555). 
sino una distorsión de su esencia y de su mensaje con graves consecuencias. La comunidad de los cristianos dejaba de ser una Iglesia martirial en seguimiento del protomártir Jesús, y cada vez más la misma Iglesia se va convirtiendo en parte de un mundo que produce víctimas, o al menos las tolera, como "daño colateral". A pesar de toda su ambigüedad, el éxodo al desierto de los primeros monjes de la Iglesia imperial y de la cultura dominante algo tiene que ver, ciertamente, con Jesús. ¿Por qué?

Parafraseando a Johann Baptist Metz, a quien debo las intuiciones fundamentales de mí teología, quiero formularlo así. Desde sus orígenes, el cristianismo es una "rebelión juvenil"4 , una rebelión juvenil dentro de una religión envejecida que ha perdido su corazón vivo en reglamentos, formalidades y jerarquías. Se rebela contra un sistema religioso que pacta con los poderes políticos, sin preocuparse de hecho por los explotados económicamente y los marginados socialmente por esos poderes. Jesús recordaba proféticamente y con plena autoridad a la religión judía sus propios orígenes: la experiencia de un Dios que saca de la esclavitud, la experiencia y la fe en un Dios que no tolera a su lado ninguna divinidad que legitima imperios de dominio y represión.

Cristianos son aquellos que siguen a Jesús, que viven a la manera de Jesús. Arriesgan sus propias vidas por ponerse de manera incondicional al lado de los vulnerables, de los atormentados y de los excluidos. Desde su origen como comunidad de Jesús, la Iglesia tiene un único derecho de existir: hacer presente el Evangelio como realidad salvadora y liberadora en las realidades que afligen y esclavizan en concreto a los seres humanos en el mundo. Los primeros monjes aparecieron exactamente en ese momento histórico, cuando la Iglesia había empezado a traicionar seriamente su propia esencia, su vocación, su misión.

En los años setenta del siglo pasado, Johann Baptist Metz definió la vida religiosa como "terapia de shock del Espíritu Santo para la gran Iglesia", como "forma institucionalizada de un peligroso recuerdo en el seno de la Iglesia"5. La vida religiosa tiene que ser el aguijón, la intranquilidad, la molestia permanente de una Iglesia que hace la paz con los poderes de este mundo. En una Iglesia aburguesada la vida religiosa tiene que reclamar con insistencia y terquedad las raíces evangélicas y la radicalidad del seguimiento de Jesús.

4. J. B. Metz, "Compasión: sobre un programa del cristianismo en la era del pluralismo cultural y religioso" (disponible en http://www.foroellacuria.org/publicaciones/Informe-3.pdf, y consultado el 19 de julio de 2011): “¿A quién, si no, se podría confiar esa provocación fundamental del mensaje de Jesús y lo que hay de exagerado en él? ¿A quién habría de podérsele confiar la idea aventurera de vivir para los otros antes de obtener algo de ellos? ¿A quién se le podría ofrecer la 'otra forma de vivir' que con ella se brinda? ¿A quién, sino precisamente a los jóvenes?”.

5. J. B. Metz, Las órdenes religiosas. Su misión en un futuro próximo como testimonio vivo del seguimiento de Cristo, Herder, Barcelona, 1988, pp. 12 y ss. 
Este lenguaje, hoy en día, en nuestra situación actual, no nos parece muy adecuado. Los religiosos europeos ciertamente no se parecen a un ejército de jóvenes rebeldes. Nos parece más prudente hablar en voz baja y comportarnos de manera más discreta. Y hablando con sinceridad, esta nueva humildad a veces me parece bastante sospechosa. Si la vida religiosa no provoca ya ningún escándalo ni irritación por su voz profética - ni dentro, ni fuera de la Iglesia-, algo anda muy mal.

\section{Nueva creación por parte del Espíritu en los quiebres de la historia}

A mi parecer, esta dinámica de los comienzos del cristianismo la volvemos a encontrar en los momentos iniciales de toda fundación auténtica, al menos en los principios de los grandes arquetipos de la vida religiosa. A lo largo de los siglos, en diferentes contextos históricos y con características distintas, se puede detectar un cierto patrón que se repite y que se puede describir así. En las rupturas de la historia y en los quiebres de las culturas encontramos una cierta configuración de la Iglesia, apegada a la cultura dominante, que junto con esta entra en crisis y llega a su fin. Así ocurrió en los siglos del derrumbe del Mundo Antiguo y del surgimiento de los pueblos bárbaros; o en los siglos XII y XIII con el ascenso de las ciudades medievales y su acumulación de riqueza, y, como consecuencia, la miseria de las mayorías empobrecidas. En estas convulsiones de transición y en los umbrales de nuevas épocas, obviamente ya no sirven las viejas recetas para asegurar la transmisión del Evangelio y del mensaje cristiano. Y precisamente en estos momentos la vida religiosa se ha mostrado muchas veces como "el truco del Espíritu Santo" contra el peso de la institución y del poder eclesial, íntimamente aferrados a las estructuras de un mundo que se hunde. Entonces, algunos atrevidos se han aventurado a emprender el éxodo: salir de las formas ya obsoletas y, al mismo tiempo, volver a los inicios. El Espíritu se ha servido de ellos para la "nueva creación" de una comunidad de hermanos en la que se hace presente Jesús con nueva frescura e inmediatez.

No se puede dudar de que hoy nos encontramos en una situación semejante, esto es, de convulsión profunda con todos los síntomas de crisis y conflicto. La configuración social e institucional de la Iglesia ha envejecido, y al parecer también la vida religiosa. Ya no responde a las exigencias y desafíos del mundo real ni a la miseria y las aflicciones que amenazan a los seres humanos de hoy. Quizá el primer paso necesario sería reconocerlo con sinceridad y sin mucha nostalgia. Que la Iglesia y la vida religiosa tengan futuro depende totalmente de una "nueva creación" por parte del Espíritu, lo que está más allá de nuestra buena voluntad dispuesta a reformas, por más sincera que sea. El "ars moriendi", el arte de no aferrarse a lo ya conocido y a liberarse de la preocupación por el propio futuro, como individuos y como comunidad, es el primer paso para que el Espíritu pueda hacer que resurja vida nueva desde huesos secos. 
Todo intento por "asegurar" la identidad del cristianismo - y mucho más, la identidad de la vida religiosa - está condenado al fracaso. La Iglesia, por sí misma, no es nada. $\mathrm{O}$ es esencialmente excéntrica o no es la Iglesia de Jesucristo. No tiene una misión, sino simplemente es misión, un ser desde Otro y un ser para los otros. No hay ninguna transmisión del Evangelio sin entregarse a los otros. Sin embargo, el peso de la institución y la tentación a "espiritualizar" el Evangelio o a ablandarlo con acomodo y comodidad burguesa expresa el peligro perenne de traicionar este su ser más íntimo. Luchando por sus propios intereses como si fuera "una finalidad en sí misma”, la Iglesia es "incapaz de ser representante de la palabra reconciliadora y salvadora para los hombres y para el mundo"6.

Frente a este peligro, el Espíritu suscita a religiosos y religiosas a ser espinas en el cuerpo eclesial, "memoria peligrosa"7 de lo que significa ser cristiano y de lo que significa ser comunidad de Jesús. Esto, que vale para la Iglesia, vale de forma eminente para la vida religiosa. No tiene ninguna identidad "en sí misma", no tenemos una misión como algo accidental. Si no somos misión, si no somos desde Otro y para los otros, no somos nada. Liberarse de la preocupación por la propia supervivencia y la propia identidad, entregarse al misterio divino en la entrega a los otros, sentir "la pasión por Dios vivida en la com-pasión por las víctimas", constituye la esencia misma de la vida religiosa.

\section{Contra el docetismo en la vida religiosa: a favor de una "mística de ojos abiertos"}

Ciertamente, un altruismo abstracto no es suficiente. Quizás nos consideramos bastante altruistas. Sin embargo, solemos ser víctimas de un autoengaño piadoso y respondemos a un mundo que ya no existe. Corremos el peligro de vivir en un mundo de ilusiones y fantasmas, y de perder el sentido de la realidad. Lo que nos saca de la irrealidad y de nosotros mismos es aventurarnos en el mundo real, entremezclarnos y vivir con personas vivas y con sus aflicciones y necesidades concretas. Nos cuestionarán y muchas veces nos sacudirán los

6. Dietrich Bonhoeffer, refiriéndose a las luchas de la Iglesia luterana alemana por su supervivencia en el contexto del Tercer Reich de Hitler, escribió estas palabras: "Nuestra Iglesia, que en estos últimos años ha luchado solamente por su supervivencia como si fuera una finalidad en sí misma, es incapaz de ser representante de la palabra reconciliadora y salvadora para los hombres y para el mundo" (D. Bonhoeffer, "Reflexiones en ocasión del bautizo de Dietrich Wilhelm Rüdiger Bethge", Widerstand und Ergebung, en DBW 8, p. 435).

7. Este concepto atraviesa toda la obra de Johann Baptist Metz y se encuentra desarrollado en forma fundamental en J. B. Metz, La fe en la historia y la sociedad, Cristiandad, Madrid, 1979, pp. 100 y ss. Véase también, J. B. Metz, Las órdenes religiosas, pp. 12 y ss. 
fundamentos de nuestras ideologías y de nuestra autoconciencia. Este proceso, además, va acompañado necesariamente de miedos, sufrimientos y todas las formas de "desolación". Vivir con los otros de verdad exige una sana capacidad para entregarse a relaciones, y esto nos transformará profundamente. Abnegación, liberarse del propio yo, perder la vida para encontrarla, nada de eso es el "arte por el arte", aunque sea un arte espiritual. En el contexto descrito se hace realidad, se convierte en una experiencia profunda e incisiva que afecta de verdad a la carne humana.

En todas sus formas, la vida religiosa es "buscar a Dios". Pero si esa búsqueda es cristiana, nunca va a ocurrir alejándose y liberándose del mundo real, del mundo concreto y físico. Erich Przywara, uno de los grandes precursores olvidados del Vaticano II, escribió una vez: "No se topa uno con Dios cavando fosos en el alma humana" ". Buscar a Dios en la introspección siempre estará muy expuesto al peligro de autoengaño causado por las propias proyecciones. El primer paso para el encuentro con Dios es el choque con lo real. Toparse con Dios es toparse con la cruda realidad que se resiste a mis manipulaciones y hace derrumbarse mis ideas y conceptos de Dios. Así lo confiesa Jon Sobrino: "Me topé con el cristianismo en Aguilares, a 30 kilómetros de San Salvador, el 12 de marzo de 1977. El padre Rutilio Grande fue asesinado con dos campesinos. Ese día, y en lo que ocurrió inmediatamente después, irrumpió un cristianismo que yo nunca había vivido ni sospechado".

Tal realidad resiste nuestras manipulaciones y hace trizas nuestras ideas y conceptos de Dios construidos por nosotros mismos. En su poema más corto, Pedro Casaldáliga, claretiano y obispo de una diócesis de una población mayoritariamente indígena en Brasil, lanza este grito fundamental: "Todo es relativo, menos Dios y el hambre".

El camino primordial para acercarse al misterio del Dios vivo es exponerse al misterio del otro ser humano. Este "otro" nunca se puede reducir a ser copia de mí mismo. No es igual a mí, sino que es el no conocido, el ajeno, muchas veces ajeno de una manera que me asusta y que me da miedo. El "otro" se me está revelando como alguien que se opone a todo tipo de apropiación por mi parte. Como alguien a quien estoy forzando y presionando, si lo trato de entender y moldear según mi propia "imagen y semejanza". Como alguien que cuestiona y desafía mi propia identidad de manera radical y amenazante. "Si uno dice: 'Yo amo a Dios', y odia a su hermano, es un mentiroso. Si no ama a su hermano, a quien ve, no puede amar a Dios, a quien no ve" (1 Juan 4, 20).

8. E. Przywara, Ringen der Gegenwart, Gesammelte Aufsätze 1922-1927, vol. 1, Augsburg, 1929, p. 243.

9. J. Sobrino, "Ser cristiano hoy", Concilium, 340 (2011), p. 253. 
Johann Baptist Metz ha definido la mística cristiana como una "mística de ojos abiertos". La experiencia cristiana de Dios no tiene nada que ver con cerrar órganos sensibles a la realidad externa, sino con un despertar, despertar de nuestros sueños y de nuestros mundos de fantasmas a este mundo real creado y amado por Dios, pero desfigurado y destrozado por una desigualdad escandalosa; a este mundo en que los seres humanos, miles y millones, sufren hambre, se encuentran amenazados por una violencia mortal y mueren una muerte prematura. Una de las preguntas que más me perturba es ¿cómo se puede trasladar el mensaje de la parábola del buen samaritano a un contexto globalizado? No es uno el que ha caído en manos de ladrones. Es una parte decisiva de la humanidad la que ha caído hoy en manos de bandidos, de los agiotistas en las bolsas, de los traficantes de armas y de los que simplemente se mueven por la codicia. La mística de la compasión que nace en la pasión por Dios no tiene otra salida que transformarse en una "mística política". Pero ¿cómo podemos vivir tal mística sin colapsar bajo la pesada carga? Metz habla de un "imperativo categórico" que inevitablemente se impone al ser humano que se resiste a cerrar los ojos. "Mira con atención y sabrás"10. ¿Aguantamos mirar de verdad esta realidad de nuestro mundo, o lo que vemos es tan abrumador, tan aplastante, que quedamos necesariamente paralizados, inundados por sentimientos de impotencia?

"El hombre no puede verme y seguir viviendo" (Éx 33, 20). Ponerse en marcha para buscar seriamente a Dios es una aventura exigente y peligrosa. La "noche oscura" y la "muerte mística" no son estados raros del alma humana. Expresan el exponerse ante Dios en la realidad de este mundo que parece ser en todo la negación clamorosa de Dios. Nelly Sachs, una de las sobrevivientes de Auschwitz, dice en uno de sus poemas más preciosos:

Solo algunos de los grandes desesperados amaron tanto

que hicieron saltar, hecho pedazos, el granito de la noche. ${ }^{11}$

\section{5. "Cristiforme" en la solidaridad activa con los pobres}

"El cristiano del futuro, o será un místico o no será". Estas palabras de Karl Rahner expresan, ciertamente, una verdad profunda y decisiva. Pero Pedro Casaldáliga ha dado un paso más y las ha precisado desde los pobres. El cristiano del futuro, o será pobre - será solidario con los pobres- o no será.

Lo he dicho a propósito de unas palabras de Karl Rahner, que escribía: "En el siglo XXI un cristiano o será místico o no será cristiano". Que conste que considero a Rahner como el mayor teólogo del siglo XX. Sin embargo, yo

10. J. B. Metz, Memoria passionis, óp. cit., p. 167. Metz está citando a Hans Jonas.

11. Nelly Sachs en "Flügel der Prophetie", citado por D. Sölle, Das Eis der Seele spalten, Grünewald, Mainz, 1996, p. 219. 
creo, con la más estremecida convicción evangélica, que hoy, ya en el siglo XXI, un cristiano o cristiana o es pobre y/o aliado o aliada visceralmente, aliado o aliada de los pobres, enrolado en la causa de los oprimidos, o no es cristiano, no es cristiana. Ninguna de las notas famosas de la Iglesia se mantiene en pie si la Iglesia olvida esta nota fundamental, la más evangélica de todas: la opción por los pobres. ${ }^{12}$

Ciertamente, Pedro Casaldáliga no está propiciando ninguna "reducción antropológica" del cristianismo o un humanismo ateo, pero insiste en dónde y cómo se realiza el encuentro con Dios. No se puede buscar seriamente a Dios sin entregarse a la lucha por un mundo más justo e igualitario. "Hacer justicia al pobre y oprimido, eso es conocer a Dios de verdad" (Jer 22, 16). En la Biblia, "conocer" es siempre más que un conocimiento racional. Conocer es el encuentro en la profundidad de la persona, la entrega total al otro. Nadie puede encontrarse con Dios si no se hace sensible a su presencia en los desprotegidos y las víctimas. Y la percepción de esta presencia lleva por sí misma a la acción y a la lucha.

La mística cristiana sí es una mística de la acción, aunque no del activismo. No sirve ni caer en fanatismos o posturas agresivas o ideológicas, ni en desesperación y apatía. El camino es más bien aceptar con sencillez nuestras limitaciones y el margen de las posibilidades de nuestra actuación, y, a la vez, activar toda nuestra energía para actuar a la manera de Jesús. "En la acción, contemplativos" es el lema de la espiritualidad ignaciana. Esto significa, en concreto, sintonizar nuestro actuar con el actuar de Jesús, un proceso progresivo de transformación del centro de nuestra persona para que sea siempre más cristiforme. Esta actividad, que exige todas nuestras energías, es al mismo tiempo totalmente dócil, pasiva, ante el actuar de Dios en nosotros. Estando en sintonía con el actuar de Jesús, configurándonos según Cristo, transformándonos en la forma del Hijo, Dios nos acoge como a hijos e hijas queridos. El punto culminante de este proceso se encuentra en la exclamación de Pablo: "Ya no vivo yo, sino que Cristo vive en mí" (Gál 2,20). Este proceso es una transformación radical, un morir del sí mismo de verdad, pero no tiene nada de alienante, sino que, al contrario, es el despertar de nuestro potencial humano en plenitud. Si la experiencia es auténtica, está transida de gozo y alegría, aunque muchas veces de alegría con lágrimas.

\section{6. "La autoridad de los que sufren"}

Todo lo que Jesús hace lo hace por obediencia al Padre, oyendo la voz del Padre. "Yo no hago nada por mí mismo... El que me ha enviado está conmigo y no me deja nunca solo, porque yo hago siempre lo que le agrada" (Juan 8,28 s).

12. Pedro Casaldáliga, citado en B. Forcano, Pedro Casaldáliga. La coherencia de una vida profética. Disponible en http://www.iglesiaviva.org/217/217-21-CONVER.pdf, y consultado el 20 de julio de 2011. 
Pero ¿cómo sabemos que no caemos en la trampa del autoengaño, que no actuamos por cuenta propia, sino que de verdad hacemos lo que agrada al Padre? En la concepción tradicional de la vida religiosa, la cosa era relativamente simple: la mediación de la voluntad de Dios es la autoridad de la Iglesia. Obedeciendo a esta autoridad cumplimos la voluntad de Dios. ¿Corresponde esto de verdad al carisma de la vida religiosa y a su vocación profética? ¿Dónde nos habla Dios de tal manera que exige nuestra obediencia incondicional y una repuesta que moviliza toda nuestra existencia? Parafraseando a Metz, la mediación de la autoridad divina es ante todo la "autoridad de los que sufren"13. Los que mueren de hambre o por causa de la violencia, como consecuencia de una desigualdad escandalosa; los migrantes, combatidos por Europa y Estados Unidos en sus fronteras del sur; y los presos políticos; en fin, todos aquellos de quienes habla el pequeño Apocalipsis en el Evangelio de Mateo (Mt 25), son ellos la autoridad máxima a la cual tenemos que responder sin rechistar. Ninguna instancia, tampoco la más alta instancia jerárquica de la Iglesia, está por encima de esta autoridad. Una obediencia y un amor adulto a la Iglesia saben que esta es la vocación más noble de la vida religiosa, el servicio que debemos de verdad a la Iglesia: someternos a la autoridad de las víctimas y reclamar proféticamente que toda la Iglesia tiene que configurarse y definirse desde esta autoridad. Si no hace esto, está deformando el rostro de Jesucristo.

\section{Misión: moverse desde el centro hacia la periferia}

En tiempos de crisis de la Iglesia, en tiempos en los que está en peligro de perder su rostro jesuánico, obviamente el Espíritu prefiere irrumpir desde los márgenes, a veces desde los márgenes aun bajo sospecha de herejía. Ya los comienzos del monacato se realizaron al margen de la gran Iglesia, de modo que la integración de los monjes fue un desafío vital para ella. Así sucedió también en el movimiento de pobreza del siglo XIII - y el ojo de la Inquisición ha estado dirigido hacia un buen número de sus fundadores-.

La misión es una dinámica centrífuga, un movimiento desde el centro hacia los márgenes. Es un movimiento hacia los marginados para hacerse sacramento de la comunión, instrumento de la inclusión de los que se encuentran excluidos. Si la vida religiosa se define como este momento eclesial que mantiene viva precisamente esta dinámica, su lugar propio es la marginalidad. Por el contrario, su gran tentación es el anhelo de pertenecer al centro o convertirse en centro. Pero cuando la vida religiosa se deja llevar por el anhelo de participar en el poder o se deja domesticar y funcionalizar por las estructuras eclesiásticas, ya no sirve como sal ni tiene sabor. Lo primero es más la versión masculina de la tentación, y por eso Ignacio de Loyola exige de los jesuitas una promesa: no solicitar ni aceptar jamás ninguna dignidad eclesiástica. Las mujeres no necesitamos tal promesa, pero no

13. Cfr. J. B. Metz, Memoria passionis, óp. cit., p. 216. 
por eso estamos en menor peligro. Para sentirnos queridas y aceptadas por el centro, traicionamos bastantes veces nuestro carisma y nos establecemos como soporte del sistema. En definitiva, el aguijón profético se ha convertido en grasa lubricante que mantiene el funcionamiento de la maquinaria eclesial.

Según Jon Sobrino, la marginalidad, como lugar propio de la vida religiosa, significa "desierto, periferia y frontera". El ambiente "natural" de la vida religiosa es allá donde nadie quiere dirigirse, allá donde no se encuentra poder, sino impotencia, y allá donde hay que arriesgarse hasta arriesgar la propia vida, "donde más necesaria sea la actividad profética para sacudir la inercia en que se vaya petrificando la Iglesia en su totalidad, o para denunciar con más energía el pecado"14. Nuestro mundo no es un lugar inocente, sino un lugar de batalla, de lucha. Los religiosos no tenemos que mantener nuestra inocencia, sino arriesgarnos de manera incondicional en favor de los más vulnerables, y así realizar nuestra entrega al misterio de Dios.

\section{Menos cordura y más locura, o el éxtasis místico}

La vida religiosa, en cierto sentido, no es esencial para la Iglesia, y esto da una gran libertad. Por eso puede concederse el lujo de no defender la propia existencia, salir de lo conocido y responder con libertad y fantasía creativa a las situaciones del mundo que gritan en busca de redención y salvación. No tenemos que portarnos necesariamente como monaguillos del sistema eclesial. La Iglesia merece nuestro amor adulto y no un servilismo infantil. Ni las estructuras eclesiásticas ni las tradiciones petrificadas de la misma vida religiosa tienen que definir nuestro ser y nuestra acción. Esto lo define exclusivamente la docilidad de sintonizar nuestro actuar con el actuar de Jesús. Cantamos la gloria de Dios al arriesgar las "exageraciones insoportables" del Evangelio y del seguimiento de Jesús. Dietrich Bonhoeffer, el gran mártir de la Iglesia luterana alemana, nos dice:

¿Cómo justificar nuestra demente arrogancia para situarnos más allá de las cosas materiales que el mismo Cristo vio y tomó absolutamente en serio? Tenemos que acabar con esta espiritualización hipócrita y engañosa del Evangelio. ¡Aceptémoslo como es u odiémoslo sin dar explicaciones! [...] ¿No es realmente cínico hablar de consuelo celestial porque no se quiere dar consuelo terrestre? [...] ¿No muestra eso que en el fondo no se toma en serio la miseria, sino que se la esconde tras frases piadosas? ${ }^{15}$

No seamos hipócritas, no vivamos en un mundo ficticio, estemos dispuestos a encarnar el amor de Dios en este mundo real.

14. J. Sobrino, Resurrección de la verdadera Iglesia. Los pobres, lugar teológico de la eclesiología, UCA Editores, San Salvador, 1986, p. 329.

15. D. Bonhoeffer, Sermón sobre San Lucas (16, 19-31), DBW 11, pp. 426-435, aquí pp. $430 \mathrm{y}$ ss. 
Si hacemos esto de verdad, va a sacudir y transformar profundamente la vida religiosa que conocemos y que hemos vivido hasta ahora. "Orden" indica algo ordenado, reglamentado, todo en su sitio, todo bajo control. ¿No es esto en cierto sentido lo contrario de la entrega? ¿Y no trae consigo el peligro de la esterilidad? "Otro te ceñirá y te llevará adonde tú no quieras" (Juan 21, 18). "Perder el control", renunciar al estatus, liberarnos de la propia importancia, esto podría ser el comienzo de una libertad desconocida y de nueva fecundidad y alegría.

La mística cristiana siempre es una mística del camino. Caminando tras Jesús, arriesgándonos como él por nuestros hermanos en peligro de sucumbir, abandonándonos al misterio de Dios. "Caminante, no hay camino, se hace camino al andar" dicen los versos preciosos de Antonio Machado. Sin embargo, no es un caminar en soledad, sino el caminar de un pueblo. Estoy en camino, junto con mis compañeros y junto con mis hermanos más vulnerables que se convierten en guías hacia el misterio de Dios.

Desde el Tercer Mundo, así responde Pedro Casaldáliga a Antonio Machado:

Haz del canto de tu pueblo

el ritmo de tu marchar.

Sacude el largo letargo,

deja nostalgias atrás.

Quien camina en la esperanza

vive su mañana ya. ${ }^{16}$

16. P. Casaldáliga, Cantares de la entera libertad, Managua, 1984, p. 47. 